\title{
16 \\ SENIOR SAFETY-A STUDY OF FALL PREVENTION IN 16 NORWEGIAN MUNICIPALITIES
}

doi:10.1136/injuryprev-2012-040580f.16

EJ Vaagland*, E Saghaug. Norwegian Safety Forum

Background Accidental injuries, particularly falls, is a hazard to health and quality of life for elderly, a burden for their relatives, and a large cost for society. In Norway app. 10000 suffer from hip fractures annually. The number of senior citizens will increase dramatically the coming years-and it will be even more important to prevent these accidents.

Objectives To demonstrate that senior safety can be improved and falls prevented by different means of cross sectorial interventions, and that cooperation between the public system and voluntary organisations gives new possibilities.

Method The 16 participating municipalities functioned as a laboratory for different fall preventing interventions, and as an arena for different types of partnerships and models of cooperation between public and private institutions and NGOs. The local programmes were based on local conditions. More than 40 NGOs participated in the local activities. The 'Senior Safety'-study was carried out by the Norwegian Safety Forum in 2007-2009. It focused on elderly above 65 years of age. Results Fall among elderly can be reduced with different means of interventions.

Cross sectorial cooperation, where community based services interact with local NGOs is a winning method. All the participating municipalities are under the Norwegian average for hip fractures.

Significance Co-operation where all parts meet on an equal terms promotes a good result. Support from local administration and local politicians is a benefit. Many of these interventions are now part of the local long-term health programmes for elderly. 